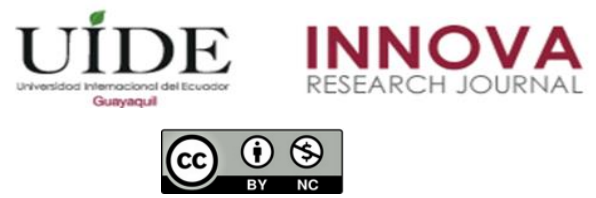

INNOVA Research Journal, ISSN 2477-9024

(Enero - Abril 2021). Vol. 6, No.1 pp. 84-110

DOI: https://doi.org/10.33890/innova.v6.n1.2021.1443

URL: http://revistas.uide.edu.ec/index.php/innova/index

Correo: innova@uide.edu.ec

\title{
Plan de intervención para estimular afectaciones cognitivas en niños y adolescentes institucionalizados
}

\section{Intervention plan to stimulate cognitive diseases in institutionalized children and teenagers}

María Belén Tinoco Sánchez

(D) https://orcid.org/0000-0002-3627-3209

Investigador independiente, Ecuador

Autor para correspondencia: tinocobelen@gmail.com

Fecha de recepción: 04 de junio de 2020 - Fecha de aceptación: 12 de octubre de 2020

\section{Resumen}

La presente investigación busca estudiar a la institucionalización como medio para acoger a los niños y adolescentes víctimas de maltrato infantil. El estudio tiene como objetivo estimular las afectaciones de las funciones cognitivas en niños y adolescentes institucionalizados mediante la elaboración de un plan de intervención neuropsicológico. La investigación es de tipo cuantitativo con un alcance de estudio exploratorio y descriptivo. El instrumento utilizado fue la Escala de Inteligencia de Weschler para niños y adolescentes, versión IV, y fue aplicado a 44 niños y adolescentes de la institución. A partir de la revisión bibliográfica y la prueba aplicada, se determinó que las alteraciones cognitivas corresponden a las áreas de Comprensión verbal, Memoria de trabajo y Velocidad de procesamiento; las funciones cognitivas conservadas están asociadas al área de Razonamiento perceptual. Finalmente, las puntuaciones del coeficiente intelectual de los evaluados corresponden a categorías debajo del promedio. Esta metodología permitió concluir que la institucionalización produce deficiencias cognitivas y no todas cuentan con un programa de intervención integral para satisfacer las demandas en cada etapa del desarrollo, especialmente a nivel cognitivo.

Palabras claves: niñez; adolescencia; institucionalización; maltrato infantil; funciones cognitivas.

\begin{abstract}
The present investigation seeks to study institutionalization as a means of welcoming children and adolescents' victims of child abuse. The study aims to stimulate the impairment of cognitive functions in institutionalized children and teenagers by developing a neuropsychological intervention plan. The research is a quantitative type with an exploratory and descriptive scope of study. The instrument used was the Weschler Intelligence Scale for children and teenagers IV and was applied to 44 children and teenagers of the institution. From the bibliographic review and the applied test, it was determined that the cognitive alterations correspond to the areas of Verbal comprehension, working memory and Processing speed; preserved cognitive functions are associated with the area of Perceptual reasoning. Finally, the intelligence quotient scores of those
\end{abstract}


evaluated correspond to below-average categories. This methodology allowed us to conclude that institutionalization produces cognitive deficiencies and not all of them have a comprehensive intervention program to satisfy the demands at each stage of development, especially at the cognitive level.

Keywords: childhood; adolescence; institutionalization; child abuse; cognitive functions.

\section{Introducción}

La institucionalización es considerada un problema social que afecta negativamente a los usuarios dentro de las residencias. Esta medida de protección social infantil se la conoce con distintos términos: hogares de protección, cuidado residencial, residencias de acogida, orfanatos, entre otros. La institucionalización se define como una forma de protección social en donde se separa al niño de sus progenitores porque sus hogares constituyen un riesgo para su integridad y crecimiento físico y psicológico (Fernández-Daza y Fernández-Parra, 2013). Estas instituciones pueden ser privadas o regidas por el estado.

En la última década, las investigaciones realizadas por varios autores han demostrado que la institucionalización tiene un impacto negativo en la cognición de los menores de edad, afectando el desarrollo del lenguaje comprensivo, morfología y sintaxis. Permite la aparición de déficit de atención, coeficiente intelectual inferior, problemas de aprendizaje, entre otros (Cabrera-Moreno y Zevallos-Herencia, 2015).

Los niños que son separados de sus hogares durante los primeros años de vida son los más afectados a nivel cognitivo, conductual y emocional. La familia constituye un papel fundamental, especialmente durante la infancia y adolescencia, ya que es la encargada de velar no solo por las necesidades biológicas del infante sino también por las necesidades afectivas, dar protección, seguridad, fomentar la socialización y evitar escenarios agresivos. En el hogar, el niño aprende a interactuar. Sin embargo, no todos los hogares constituyen el medio idóneo para la integridad y el desarrollo evolutivo. Las causas de institucionalización son varias. Entre ellas encontramos: violencia intrafamiliar, familias disfuncionales, abuso físico y sexual, pobreza, abandono, entre otros.

Un ambiente seguro para el infante permite un desarrollo neuropsicológico adecuado y el desenvolvimiento de las funciones cognitivas acorde a la edad del individuo. Las funciones cognitivas son procesos mentales que permiten llevar cabo distintas actividades y desenvolvernos en el medio ambiente. Mediante las funciones cognitivas las personas son capaces de seleccionar, receptar, almacenar, transformar, elaborar y recuperar información. El desarrollo de estas funciones es progresivo y continuo, es decir, el sistema nervioso constituye cambios constantes en cada etapa del sujeto que le ayudan en su adaptación social.

Los niños y adolescentes víctimas de abuso sexual y físico, pobreza, abandono, carencias afectivas, espectadores de violencia en relaciones parentales son vulnerables para el desarrollo adecuado a nivel cognitivo, conductual y emocional. El 10\% de los niños en América Latina viven en un hogar de protección, específicamente 374.308 infantes. A nivel nacional, $9.7 \%$ de niños expuestos a situación de riesgo se encuentran en residencias de acogida, el $47.8 \%$ de estos 
niños tienen entre 13 y 18 años de edad, seguido por el $41.79 \%$ que tienen entre 5 y 12 años y luego el 10.36\% que tienen de 0 a 4 años de edad (Robalino-Buenaño \& Carranza-Villamar, 2017).

Otra problemática de la institucionalización es que no todos los hogares de acogida cuentan con el personal adecuado para brindar apoyo psicológico y social, velar por el estado físico de cada residente y cubrir con los gastos educativos que demanda cada individuo. Por lo tanto, la falta de educación, estimulación temprana, exposición a eventos traumáticos durante la infancia suponen obstáculos para el desarrollo neuropsicológico adecuado.

La presente investigación tiene como objetivo principal estimular las afectaciones de las funciones cognitivas en niños y adolescentes institucionalizados, mediante los siguientes objetivos específicos:

- Identificar las necesidades en la infancia para un adecuado desarrollo afectivo, psicológico y social.

- Identificar las principales consecuencias que produce la institucionalización.

- Determinar las funciones cognitivas alteradas y conservadas de los niños y adolescentes institucionalizados.

- Elaborar un plan de intervención para estimular las funciones cognitivas que presentan alteraciones y promover un desarrollo neuropsicológico adecuado.

\section{Marco teórico}

\section{Maltrato infantil}

Según Unicef (2015), 6 de cada 10 niños en el mundo son víctimas de maltratos físicos por parte de sus tutores y 1 de cada 10 niños han sufrido abuso sexual. Otros estudios señalan que el $20 \%$ de las mujeres y del $5 \%$ al $10 \%$ de los hombres afirman haber sido víctimas de abuso sexual durante su niñez; y un 25\% al 50\% haber sufrido maltrato físico (Diaz-Leguizamón, 2014).

El Código de la niñez y adolescencia en el artículo 67 postula:

Se define maltrato infantil a cualquier conducta, acción u omisión que provoque daño a la integridad física, psicológica y sexual del niño o adolescente por cualquier sujeto, ya sea progenitores, cuidadores o educadores. Se incluyen en esta calificación el trato negligente o descuido grave o reiterado en el cumplimiento de las obligaciones con los niños, niñas y adolescentes, relativas a la prestación de alimentos, atención médica educación o cuidados diarios; y su utilización en la mendicidad (Asamblea Nacional, 2014).

La Organización Mundial de la Salud (OMS) establece cuatro tipos de maltrato infantil: 


\section{Tabla 1}

Tipos de maltrato infantil

\begin{tabular}{ll}
\hline Tipos de maltrato & \multicolumn{1}{c}{ Características } \\
\hline Abuso físico & $\begin{array}{l}\text { Se considera uso extremo de fuerza física contra un menor de } \\
\text { edad que provoque daño o perjuicio hacia el desarrollo de su } \\
\text { dignidad, salud y supervivencia. }\end{array}$ \\
Abuso sexual & $\begin{array}{l}\text { Hace referencia a la participación de un menor de edad en } \\
\text { actividades sexuales impuestas por adultos u otros niños sin } \\
\text { consentir la acción o no tener conocimiento pleno de la } \\
\text { participación en la actividad. }\end{array}$ \\
Abuso psicológico & $\begin{array}{l}\text { Puede presentarse en acontecimientos disfuncionales o } \\
\text { incidentes por parte del cuidador o padres en el contexto en que se } \\
\text { desenvuelve el niño y el cual carece del apoyo y necesidades } \\
\text { básicas para el desarrollo del infante. }\end{array}$ \\
Hesatención & $\begin{array}{l}\text { Hace referencia a la carencia de condiciones básicas que los } \\
\text { niños y adolescentes deben tener para su óptimo desarrollo. Estos } \\
\text { son: salud, nutrición, educación, hogar y afecto. }\end{array}$
\end{tabular}

Fuente: Adaptada de: "Prevención del maltrato infantil: Qué hacer y cómo obtener evidencias" de (Butchart, Phinney-Harvey, Mian, Furniss, \& Kahane, 2009).

Como consecuencias del maltrato infantil, los niños y adolescentes son vulnerables a implicarse en delitos, problemas legales, consumo de sustancias psicoactivas, ausentismo escolar, relaciones sexuales precoces y psicopatologías, tales como, depresión, ideaciones suicidas, trastornos alimentarios, estrés postraumático y trastornos disociativos (FernándezFernández, 2014).

\section{Institucionalización en menores de edad víctimas de maltrato}

Debido a que los primeros años de vida son fundamentales para un correcto desarrollo cognitivo, conductual y emocional de la persona, los menores de edad que se encuentran en vulnerabilidad y que requieran de una protección integral, habitan en casas de acogida, hogares o residencias. La institucionalización es un proceso de protección transitorio regido por el estado o una entidad autónoma en el que trabajan en conjunto profesionales de la salud, tales como, médicos, psicólogos y trabajadores sociales para proveer al niño o adolescente la ayuda necesaria para garantizar un óptimo desarrollo. Además, la institucionalización no pretende reemplazar a la familia, por lo que, uno de sus principales objetivos es velar para que los menores de edad puedan ser reinsertados en su ambiente familiar (padres, tíos o abuelos), se reintegre a una familia diferente (adopción), y en caso de que no se puedan cumplir las opciones anteriores, preparar al sujeto para la independencia cuando sea mayor de edad (Quezada-Moncada, 2016). 


\section{Desarrollo de la infancia}

En la infancia, cada niño tiene necesidades que deben satisfacerse en cada etapa de desarrollo, es decir, un niño de meses no tiene las mismas demandas de un infante de $5-6$ años. Atender las necesidades infantiles va a permitir que el niño pueda desarrollar habilidades cognitivas, conductuales y emocionales adaptativas para desenvolverse funcionalmente en su entorno. Las demandas que las instituciones deben cubrir en cada infante son: necesidades de seguridad, desarrollo cognitivo/lingüístico y desarrollo socioemocional.

Las demandas relacionadas a la seguridad se refieren a las necesidades biológicas que cada persona posee para poder vivir (alimentación, salud) y garantizar un apropiado desarrollo físico. Las necesidades cognitivo/lingüístico se relacionan con la capacidad del infante de poder desarrollar sus funciones ejecutivas y que estas le permitan entender y estructurar las vivencias y situaciones diarias. Finalmente, las necesidades socioemocionales hacen referencia a los elementos afectivos con que los infantes deben contar para poder desarrollar una óptima expresión afectiva y una adecuada interacción social (Jimeno-Jimenez, 2016).

La teoría del apego, descrita por Bowlby, describe la base para que el niño pueda desarrollar habilidades sociales y emocionales en el futuro. La figura del apego hace referencia al sujeto que brinda al infante seguridad en situaciones en las que el niño se encuentra vulnerable, es decir, peligro, estrés y tensión. Esta figura de apego, bajo la protección del cuidador, genera el aprendizaje para afrontar "experiencias traumáticas" y permite al niño explorar e interactuar con el medio, es decir, el niño debe contar con una figura segura y protectora que no solo cubra sus demandas emocionales, sino que le permita aprender a relacionarse adecuadamente con personas y objetos (Salinas-Quiroz y Posada, 2015).

\section{Afectaciones psicológicas de la institucionalización}

Estudios revelan que cada tres meses que un infante o adolescente permanece en una institución, pierde un mes de desarrollo (Palummo, 2013). Además, en algunos niños, la soledad, el temor e incertidumbre de vivir en una institución y lejos de su hogar por la ruptura de vínculos familiares o por las características que presenta la casa de acogida, puede ser un factor para generar en el menor de edad la aparición de problemas psicológicos o agravar síntomas psicopatológicos existentes (Fernández-Daza, 2013).

Investigaciones realizadas por autores han permitido determinar las alteraciones neurobiológicas que el infante puede presentar por estar institucionalizado. Según FernándezDaza (2013), cuando la institucionalización tiene una duración larga, es decir, mayor a seis meses, en el niño existe una alteración en el desarrollo cerebral, disfunciones en el cuerpo calloso, amígdala e hipocampo y aumento del cortisol por la escasa interacción social. Estas alteraciones neuropsicológicas, pueden causar déficit de atención, hiperactividad, impulsividad, deterioro cognitivo (atención, memoria y lenguaje) y problemas conductuales.

Además, los niños pueden presentar afectaciones en las funciones cognitivas, especialmente en cuatro áreas: 


\section{Tabla 2}

Afectaciones en las funciones cognitivas

\begin{tabular}{cl}
\hline Afectaciones cognitivas & \multicolumn{1}{c}{ Características } \\
\hline Comprensión verbal & $\begin{array}{l}\text { Hace referencia a la elaboración de conceptos verbales, } \\
\text { razonamiento verbal y conocimiento adquirido del entorno } \\
\text { ambiental. }\end{array}$ \\
Razonamiento perceptual & $\begin{array}{l}\text { Involucra destrezas, tales como: integración visomotora, } \\
\text { procesamiento espacial y razonamiento perceptivo. Esta función } \\
\text { permite desarrollar tareas que involucren análisis y síntesis de un } \\
\text { diseño, análisis visual, conceptualización abstracta y } \\
\text { discriminación de figura - fondo. }\end{array}$ \\
& $\begin{array}{l}\text { Está asociado a la atención, razonamiento, concentración y } \\
\text { control mental, permitiendo la conservación de información por } \\
\text { un determinado tiempo para poder ejecutar o manipular el }\end{array}$ \\
& contenido y obtener un resultado. \\
Hemoria de trabajo & $\begin{array}{l}\text { Hace referencia a la discriminación rápida y correcta de la } \\
\text { información visual. Está relacionada con la memoria a corto y } \\
\text { procesamiento }\end{array}$ \\
& largo plazo, capacidad para rastrear y seguir secuencias. \\
\hline
\end{tabular}

Fuente: Adaptada de: "Escala Wechsler de Inteligencia para Niños-IV" de (Wechsler, 2007).

Asimismo, los infantes que habitan en casas de acogida tienen mayor prevalencia a presentar problemas conductuales y emocionales, por ejemplo, depresión, ansiedad e inhibición. Los altos índices de ansiedad hacen referencia a que los niños se sienten amenazados por su entorno debido a los cambios que han tenido que afrontar, tales como, problemas y ruptura de vínculos familiares, conflictos escolares, nuevas relaciones sociales, adaptación al medio y nuevas reglas a seguir (Cunha y Barreyro, 2015). Además, esta población puede presentar dificultades en sus habilidades sociales por la desconfianza, escaso afecto, actitudes de sospecha y agresiones que han observado y vivido en su entorno. Por lo tanto, tienen dificultades para establecer y mantener una apropiada interacción con sus pares (Mansilla-Yuguero, Olaya-Meza, y Picazo-Ortega, 2018).

Otras afectaciones que pueden presentar los niños y adolescentes institucionalizados son: desarrollo de apego inseguro, trastornos de conducta, trastorno de sueño, trastornos alimentarios, déficit de atención, impulsividad, agresividad, retraso en el desarrollo psicomotor, problemas de aprendizaje y movimientos estereotipados. En los adolescentes, una de las alternativas que ayudan en el proceso de institucionalización es fortalecer las habilidades sociales y, estudios muestran que, el comportamiento social puede desarrollarse y mantenerse aún en condiciones adversas (Fernández-Daza y Fernández-Parra, 2017).

Sin embargo, es importante destacar que estas instituciones deberían contar con un equipo de profesionales capacitados para atender las demandas de cada niño, los mismos que deben estar conformados por: psicopedagogos, médicos, psicólogos, asistentes sociales y 
cuidadores. Asimismo, las residencias velan por cubrir las necesidades físicas que los infantes necesitan, tales como: alimentación, educación, actividades, espacios recreacionales, protección, asistencia médica y psicológica. Además, el contexto institucional le ayuda al niño y adolescente a desarrollar autonomía e independencia (Arguello, González, y Joubert, 2015).

\section{Metodología}

La presente investigación es de tipo cuantitativo y con un alcance de estudio exploratorio y descriptivo ya que el tema ha sido poco abordado y por ser una problemática actual es necesario responder a las interrogantes que se tienen acerca del mismo. Además, se pretende especificar y describir las afectaciones cognitivas que produce la institucionalización en los infantes y adolescentes del hogar estudiado.

El método de muestreo utilizado es no probabilístico y de carácter de conveniencia o intencional para obtener una representación significativa de niños institucionalizados. Este tipo de muestras son frecuentes en estudios de ciencias sociales ya que las herramientas que se utilizan en una determinada población cuentan con requisitos para el desarrollo de esta, por lo que, el investigador procura que los sujetos sean homogéneos en variables como: edad, sexo, inteligencia, entre otros. La utilidad de este método de estudio no es proporcionar una mayor representatividad de la población sino contar con una población que cumple con características específicas para el planteamiento del problema (Hernández, Fernández, y Baptista, 2004).

La población de la institución la constituyen 57 infantes femeninos y masculinos (40 niños y 17 adolescentes). La edad oscila en un rango de 3 a 16 años. Este centro fue escogido para llevar a cabo el estudio porque se caracteriza en acoger a infantes y adolescentes provenientes de hogares disfuncionales que han sufrido abuso sexual o físico, maltrato, abandono y negligencia. Los niños son llevados a la casa de protección a través del Ministerio de Inclusión Económica y Social (MIES). Asimismo, en el hogar reciben atención psicológica, educación y formación en valores.

Debido a que el muestreo utilizado es de conveniencia, la muestra recogida fue de 44 niños y adolescentes. Los 13 residentes restantes de la institución no pudieron realizar la prueba psicométrica debido a que no cumplían con ciertos requisitos indispensables para el desarrollo de la misma, es decir, su edad es inferior a 6 años o presentan trastornos del neuro-desarrollo. Los resultados fueron analizados a través del programa Microsoft Excel.

\section{Instrumento}

El instrumento utilizado fue la prueba psicométrica, Escala de Inteligencia de Weschler para niños (WISC-IV), que evalúa la capacidad cognoscitiva de los infantes entre los 6 a 16 años de edad. El objetivo del test es medir el desarrollo cognitivo de las personas a través de cuatro escalas principales: comprensión verbal, razonamiento perceptivo, memoria de trabajo y velocidad de procesamiento (Wechsler, 2007). Para obtener el coeficiente intelectual, la persona deberá desarrollar diez actividades relacionadas a las escalas mencionadas. La aplicación del instrumento se llevó a cabo de forma individual, entre los meses de enero a abril del 2018. 


\section{Figura 1}

\section{Resultados}

Puntuaciones escalares del área de comprensión verbal en niños y adolescentes institucionalizados

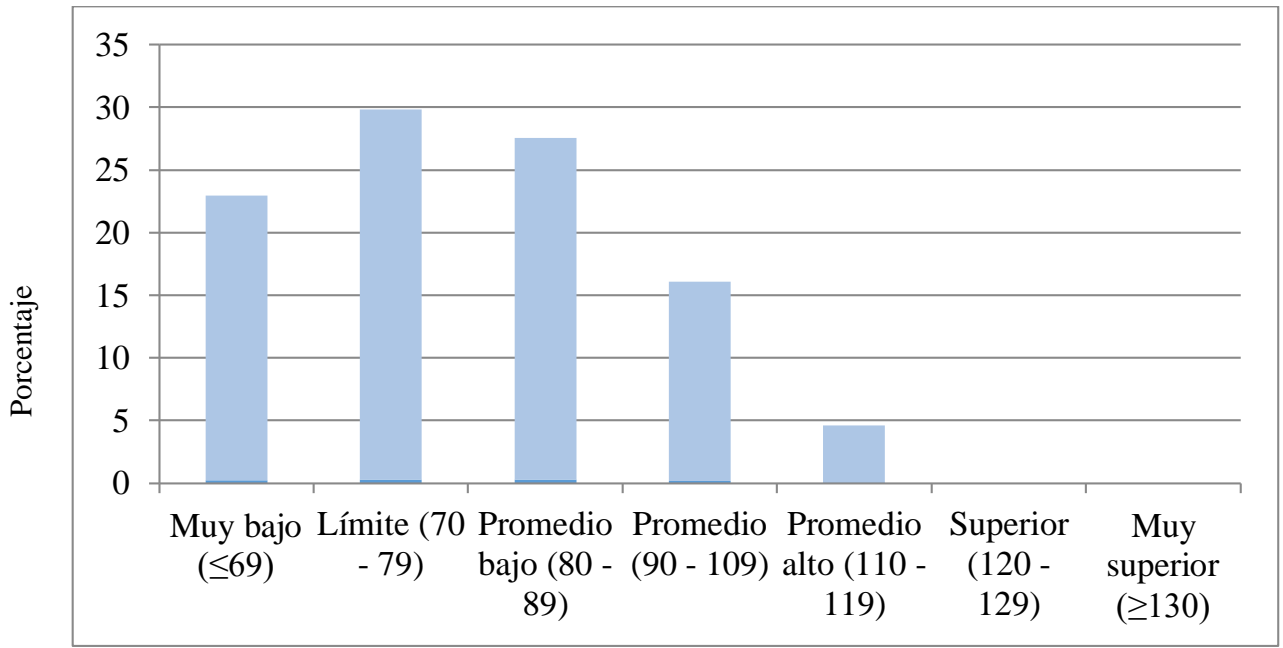

En la figura 1 se observa que el $79.53 \%$ de los evaluados presentan una puntuación debajo del promedio, es decir, $22.72 \%$ se encuentra en la categoría Muy bajo (10 niños), el $29.54 \%$ en Límite (13 niños) y el $27.27 \%$ en Promedio bajo (12 niños), en el cual destacan deficiencias en conceptos verbales, razonamiento verbal y conocimiento adquirido del entorno ambiental. La privación del ambiente y la falta de estimulación en el lenguaje pueden ser posibles causas de un déficit en esta área. Asimismo, esto puede desencadenar un bajo rendimiento escolar por dificultades en el aprendizaje verbal.

\section{Figura 2}

Puntuaciones escalares del área de razonamiento perceptual en niños y adolescentes institucionalizados

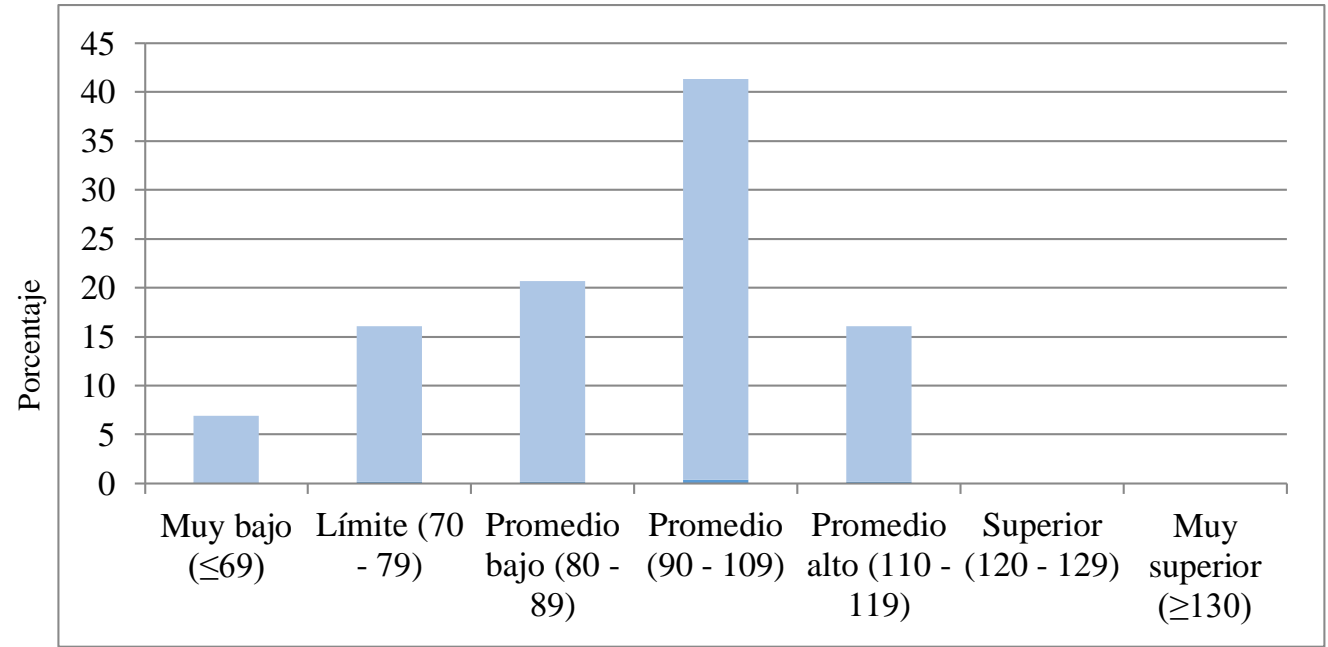


La figura 2 reflejan que el $43.16 \%$ de los evaluados presentan puntuaciones correspondientes a las categorías: Muy bajo (3 niños), Límite (7 niños) y Promedio bajo (9 niños). Sin embargo, el 56.8\% de los niños puntúan en categorías referentes a Promedio (18 niños) y Promedio alto ( 7 niños). La población que no muestra deficiencias en esta área puede tener un buen rendimiento académico debido a que la capacidad no verbal de los infantes no se ve afectadas y las habilidades para integrar y conceptualizar símbolos abstractos permiten una correcta comprensión en contenido de materias, tales como: geometría, dibujo, matemáticas, ente otros.

\section{Figura 3}

Puntuaciones escalares del área de memoria de trabajo en niños y adolescentes institucionalizados

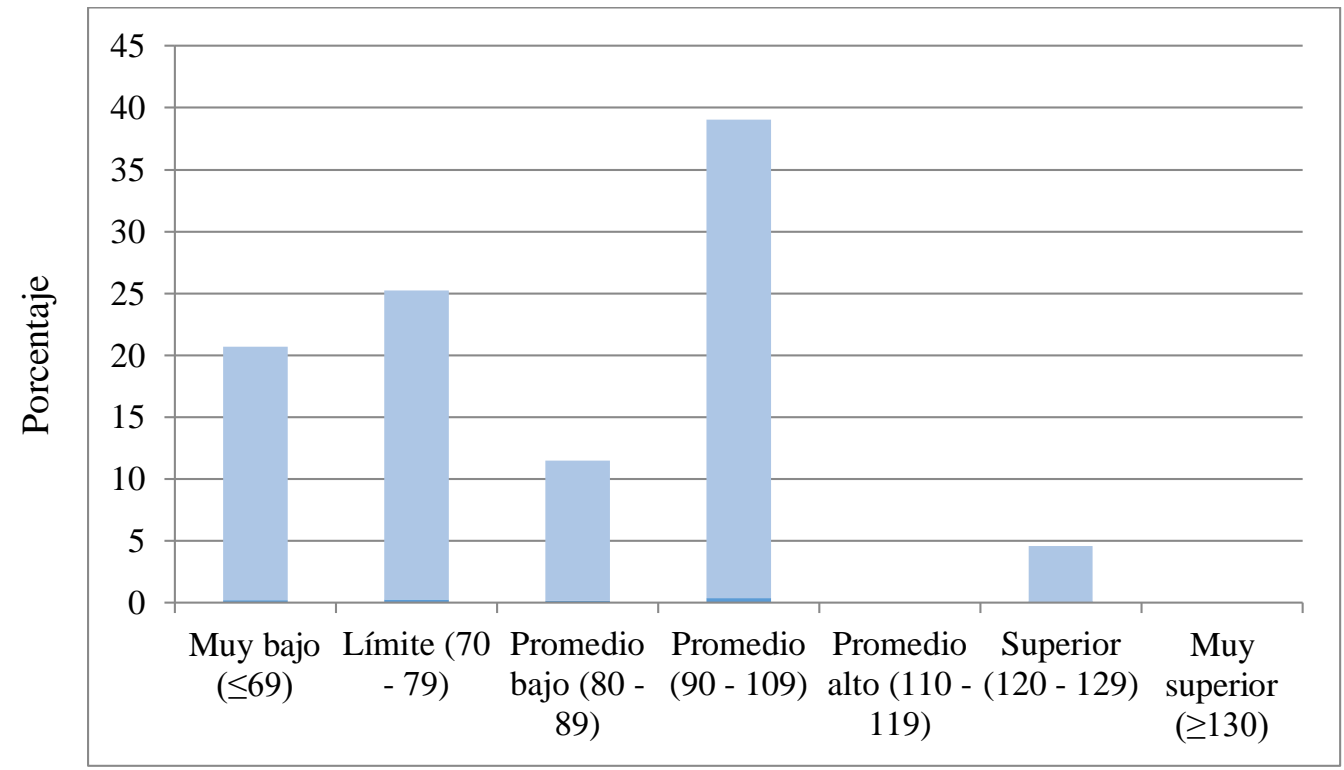

Los resultados de la figura 3 destacan que el $56.81 \%$ de los niños presentan puntuaciones debajo del promedio. El 20.45\% se encuentra en la categoría Muy bajo (9 niños), el 25\% en Límite (11 niños) y el $11.36 \%$ en Promedio bajo (5 niños). Mientras que las puntuaciones del $43.17 \%$ de los evaluados reflejan no tener alteraciones en esta área. Las deficiencias en esta escala pueden generar dificultades en el aprendizaje y aprovechamiento ya que pueden tener dificultades para conservar información por un determinado tiempo dentro de la memoria para luego poder ejecutar o manipular el contenido y obtener un resultado. 


\section{Figura 4}

Puntuaciones escalares del área de velocidad de procesamiento en niños y adolescentes institucionalizados

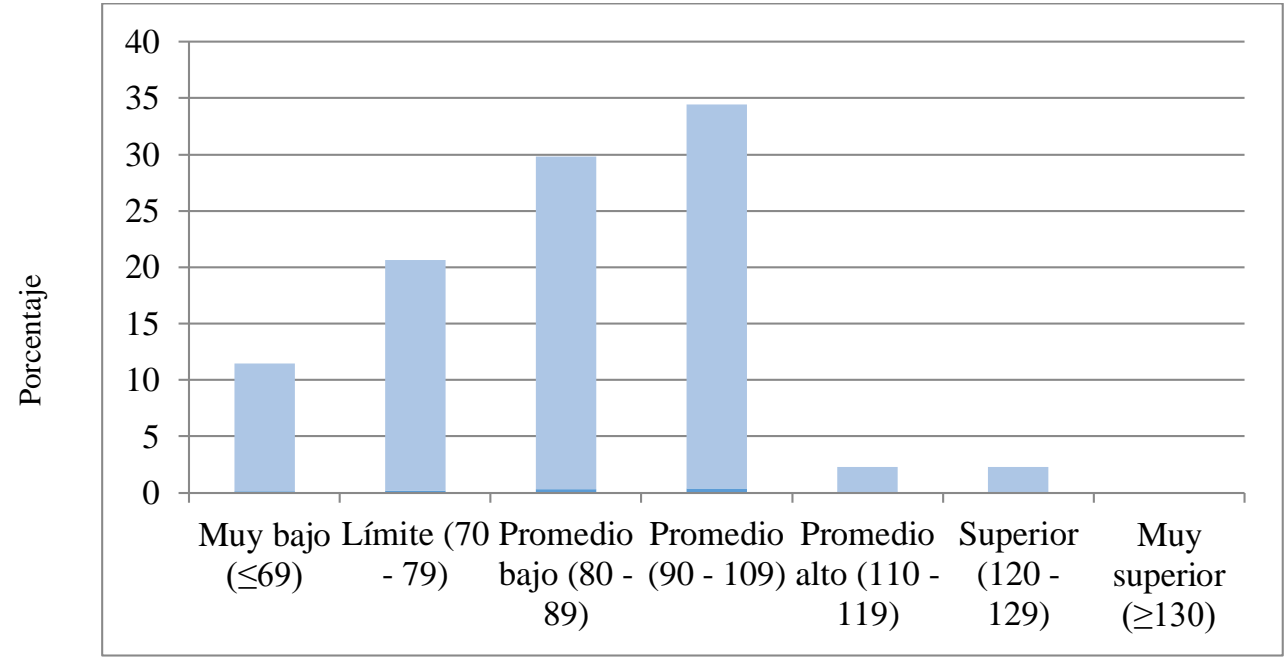

Los resultados en el área de Velocidad de procesamiento muestran que predominan las puntuaciones debajo del promedio: Muy bajo (11.36\%), Límite (20.45\%) y Promedio bajo (29.54\%). Mientras que el $38.63 \%$ se encuentra entre las categorías de Promedio, Promedio alto y Superior. Debido a que esta área está asociada a funciones ejecutivas de la memoria, los niños que presentan alteraciones muestran afectaciones en la capacidad para conservar recursos asociados a la memoria de trabajo.

\section{Figura 5}

\section{Coeficiente intelectual en niños y adolescentes institucionalizados}

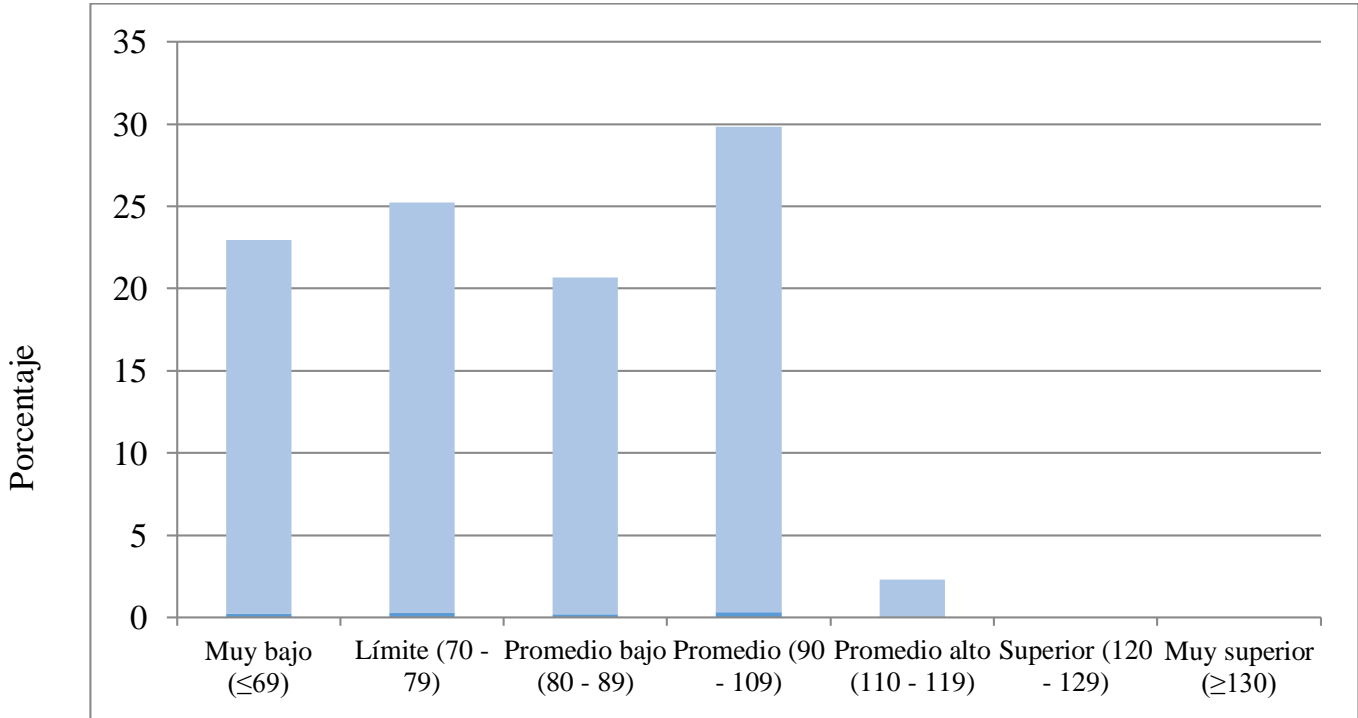


Los resultados asociados al coeficiente intelectual reflejan que el $74.99 \%$ de los evaluados tienen un CI entre 70 y 109, en el cual el 29.54\% está en el rango Promedio. Sin embargo, el $22.72 \%$ de los infantes (10 niños) presentan deficiencia intelectual, es decir, un CI inferior a 70. Aunque la mayoría de los niños no presenta deficiencia intelectual, las puntuaciones bajas en el CI están asociadas a las puntuaciones en las otras áreas evaluadas. Por lo tanto, los niños y adolescentes pueden tener dificultades en la resolución de problemas, razonamiento, pensamiento abstracto, aprendizaje y déficit en funciones ejecutivas.

\section{Figura 6}

\section{Áreas cognitivas de niños y adolescentes institucionalizados}

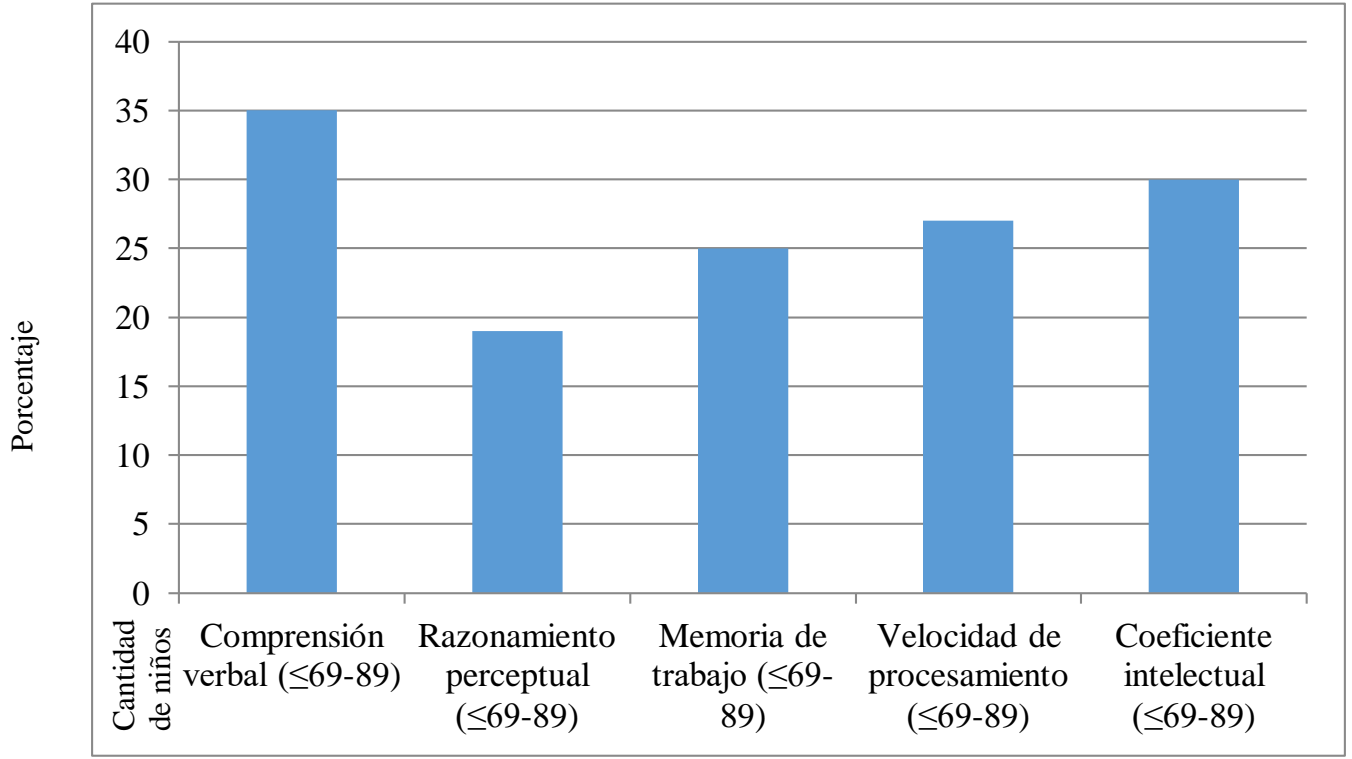

La figura 6 detalla la cantidad de niños de cada área cognitiva que puntúan entre las categorías de Muy bajo, Límite y Promedio Bajo, en el cual destacan que la mayor área con afectaciones cognitivas es Comprensión verbal (35 niños). En el área de Velocidad de procesamiento hay 27 niños que muestran deficiencias y 25 infantes con alteraciones en Memoria de trabajo. Además, el área con menos afectaciones es Razonamiento perceptual ya que 19 niños indican tener puntuaciones debajo del promedio. Finalmente, más de la mitad de los evaluados (30 niños) presentan un Coeficiente intelectual entre $\leq 69-89$ debido a las afectaciones cognitivas anteriormente mencionadas.

\section{Discusión}

A partir de los resultados obtenidos, se puede determinar que los niños institucionalizados presentan deficiencias en tres áreas cognitivas: Comprensión verbal, Velocidad de procesamiento y Memoria de trabajo. La función cognitiva que presenta mayor alteración es Comprensión verbal. Por lo tanto, las alteraciones en estas áreas impiden al infante tener un buen desempeño 
académico, limita el desarrollo de la autonomía y comunicación con sus pares y autoridades ya que el niño tiene escasa capacidad para la formación y entendimiento de vocablos, relacionar definiciones verbales, capacidad expresiva, elaboración de conceptos alternos e integración de información.

Otras dificultades se evidencian en el aprendizaje, percepción, coordinación visual y motriz, atención sostenida y selectiva, memoria a corto y largo plazo. Asimismo, incapacidad para seguir secuencias, razonamiento abstracto, planificación, dificultades en la aritmética, asociación de información, manipulación y elaboración de nueva información.

Estas deficiencias no solo influyen en la cognición sino en la adaptación a un nuevo ambiente (institución), y sin el apoyo necesario, los déficits adaptativos pueden generar limitaciones en actividades de la vida cotidiana, por ejemplo, rendimiento académico, escasas habilidades sociales, dificultades para la independencia y reinserción familiar, aparición o exacerbación de síntomas psicopatológicos.

Investigaciones realizadas en el Ecuador y otros países, destacan resultados similares a los concluidos en esta investigación. Robalino-Buenaño y Carranza-Villamar (2017) señalan que, a través de la aplicación de la Evaluación Neuropsicológica Infantil (ENI) los niños institucionalizados muestran alteraciones en las siguientes funciones cognitivas: memoria (56\%), atención (55\%), funciones ejecutivas (68\%) y habilidades del rendimiento académico (62\%). Por lo tanto, presentan escasa concentración y dificultades para retener información.

Según Deambrosio, de Vásquez, Arán-Filippetti, \& Román (2017), la exposición a situaciones que producen estrés crónico y el maltrato infantil genera deficiencias en la cognición debido a que se produce una alteración en el eje hipotalámico pituitario adrenal (HPA), amígdala, hipocampo, cuerpo calloso, altos niveles de catecolaminas que afectan el de sarrollo cognitivo y cerebral. Asimismo, se han encontrado alteraciones en las áreas frontales y temporales, lo que genera deficiencias en el aprendizaje, memoria y lenguaje.

Finalmente, un aspecto a destacar es la baja puntuación en el coeficiente intelectual de la población evaluada y, en algunos niños, posibles indicadores de Discapacidad intelectual. Según American Psychiatric Association (2014), este trastorno del neuro-desarrollo se caracteriza por presentar deficiencias intelectuales (razonamiento, resolución de problemas, razonamiento abstracto, aprendizaje a partir del entorno), deficiencias en el comportamiento adaptativo, autonomía, limitación en actividades diarias como participación social, independencia y comunicación en los entornos en que se desenvuelve la persona.

\section{Plan de intervención}

Debido a los resultados obtenidos, se ha elaborado un programa neuropsicológico para estimular las funciones cognitivas alteradas, desarrollar habilidades cognitivas de acuerdo con la edad cronológica y mejorar el rendimiento académico de los niños y adolescentes. El plan de intervención está dirigido a los niños y adolescentes que residen en la institución en que se llevó a cabo el estudio. Las actividades propuestas pueden ser aplicadas de forma individual para lograr los objetivos propuestos y evaluar el progreso de los niños. 


\section{Tabla 3}

Plan de intervención neuropsicológico para estimular las funciones cognitivas

\begin{tabular}{|c|c|c|}
\hline $\begin{array}{l}\text { Funciones } \\
\text { cognitivas }\end{array}$ & Actividades & Objetivo \\
\hline \multirow[t]{7}{*}{$\begin{array}{l}\text { Comprensión verbal } \\
\text { (véase Anexo 1) }\end{array}$} & $\begin{array}{l}\text { Actividad 1: Completar } \\
\text { categorías }\end{array}$ & $\begin{array}{l}\text { Desarrollar habilidades lingüísticas } \\
\text { mediante la evocación y adquisición } \\
\text { de vocablos. }\end{array}$ \\
\hline & $\begin{array}{l}\text { Actividad 2: Completar } \\
\text { oraciones }\end{array}$ & $\begin{array}{l}\text { Estimular el razonamiento verbal y la } \\
\text { gramática a través de situaciones } \\
\text { contextuales o refranes. }\end{array}$ \\
\hline & Actividad 3: Sinónimos & $\begin{array}{l}\text { Identificar vocablos con significado } \\
\text { similar para generar una mejor } \\
\text { comunicación y compresión de } \\
\text { términos. }\end{array}$ \\
\hline & $\begin{array}{l}\text { Actividad 4: Definición de } \\
\text { palabras }\end{array}$ & $\begin{array}{l}\text { Aumentar el léxico y la capacidad } \\
\text { para elaborar conceptos verbales. }\end{array}$ \\
\hline & $\begin{array}{l}\text { Actividad 5: Ordena las } \\
\text { fichas }\end{array}$ & $\begin{array}{l}\text { Estimular la comprensión sobre los } \\
\text { elementos que forman una } \\
\text { determinada categoría. }\end{array}$ \\
\hline & $\begin{array}{l}\text { Actividad 6: Ordenar } \\
\text { palabras }\end{array}$ & $\begin{array}{l}\text { Desarrollar la capacidad de } \\
\text { elaboración y comprensión del } \\
\text { lenguaje a través del ordenamiento de } \\
\text { palabras que formen una frase con } \\
\text { sentido gramatical. }\end{array}$ \\
\hline & $\begin{array}{l}\text { Actividad 7: Cuentos e } \\
\text { historias }\end{array}$ & $\begin{array}{l}\text { Estimular la comprensión lectora } \\
\text { mediante la identificación de ideas } \\
\text { principales. }\end{array}$ \\
\hline \multirow{2}{*}{$\begin{array}{l}\text { Razonamiento } \\
\text { perceptual (véase } \\
\text { Anexo 2) }\end{array}$} & Actividad 1: Patrón & $\begin{array}{l}\text { Identificar una secuencia lógica a } \\
\text { través del reconocimiento de los }\end{array}$ \\
\hline & $\begin{array}{l}\text { Actividad 2: Relacionar } \\
\text { figuras }\end{array}$ & $\begin{array}{l}\text { estímulos visuales presentados. } \\
\text { Ejercitar el análisis visual e } \\
\text { integración de información. }\end{array}$ \\
\hline \multirow[t]{4}{*}{$\begin{array}{l}\text { Memoria de trabajo } \\
\text { (véase Anexo 3) }\end{array}$} & $\begin{array}{l}\text { Actividad 1: Memorizar } \\
\text { figuras y signos }\end{array}$ & $\begin{array}{l}\text { Fomentar la asociación de estímulos } \\
\text { mediante características } \\
\text { visoperceptuales. }\end{array}$ \\
\hline & $\begin{array}{l}\text { Actividad 2: Juego de } \\
\text { categorías }\end{array}$ & $\begin{array}{l}\text { Retener información inmediata y } \\
\text { manipularla para obtener un resultado. }\end{array}$ \\
\hline & Actividad 3: Series de letras & $\begin{array}{l}\text { Estimular la memoria a través de la } \\
\text { elaboración de series ordenadas } \\
\text { mediante un patrón de secuencia. }\end{array}$ \\
\hline & $\begin{array}{l}\text { Actividad 4: Completar } \\
\text { series }\end{array}$ & $\begin{array}{l}\text { Aumentar y retener la mayor cantidad } \\
\text { de datos para producir una respuesta. }\end{array}$ \\
\hline
\end{tabular}




\begin{tabular}{|c|c|c|}
\hline $\begin{array}{l}\text { Funciones } \\
\text { cognitivas }\end{array}$ & Actividades & Objetivo \\
\hline \multirow{6}{*}{$\begin{array}{l}\text { Velocidad de } \\
\text { procesamiento (véase } \\
\text { Anexo 4) }\end{array}$} & $\begin{array}{l}\text { Actividad 5: Memorizar } \\
\text { tareas }\end{array}$ & $\begin{array}{l}\text { Estimular la memoria a corto plazo a } \\
\text { través de características lingüísticas. }\end{array}$ \\
\hline & $\begin{array}{l}\text { Actividad 1: Números con } \\
\text { símbolos }\end{array}$ & $\begin{array}{l}\text { Aumentar la precisión de selección de } \\
\text { respuestas entre fuentes distractores. }\end{array}$ \\
\hline & $\begin{array}{l}\text { Actividad 2: Encerrar } \\
\text { símbolos }\end{array}$ & $\begin{array}{l}\text { Ejercitar la capacidad atencional } \\
\text { mediante la selección de información e } \\
\text { inhibir fuentes alternas. }\end{array}$ \\
\hline & $\begin{array}{l}\text { Actividad 3: Encerrar } \\
\text { categorías }\end{array}$ & $\begin{array}{l}\text { Aumentar la precisión de selección de } \\
\text { respuestas entre fuentes distractores. }\end{array}$ \\
\hline & $\begin{array}{l}\text { Actividad 4: Ubicar los } \\
\text { signos }\end{array}$ & $\begin{array}{l}\text { Estimular la atención visoespacial } \\
\text { mediante información visual. }\end{array}$ \\
\hline & $\begin{array}{l}\text { Actividad 5: Operaciones } \\
\text { numéricas con símbolos }\end{array}$ & $\begin{array}{l}\text { Ejercitar la concentración y atención } \\
\text { sostenida de estímulos. }\end{array}$ \\
\hline
\end{tabular}

Fuente: Elaboración propia (basado en "Escala Wechsler de Inteligencia para Niños IV" de Wechsler, 2007. México D.F.: Editorial El Manual Moderno para actividades de Comprensión verbal y Razonamiento perceptual; “¿Problemas de memoria? Un programa para su estimulación y rehabilitación” (1 $1^{\mathrm{a}}$ ed.) de Ostrosky-Solís, F., ChayoDichy, R., Gómez, E., y Flores, J., 2005. México D.F.: LP Editorial para actividades de Memoria de trabajo; “¿Problemas de atención? Un programa para su estimulación y rehabilitación” (1ª ed.) de Ostrosky-Solís, F., Gómez, E., Chayo-Dichy, R., y Flores, J., 2004. México D.F.: American Book Store para actividades de Velocidad de procesamiento)

Aunque los resultados obtenidos de la investigación son fundamentales y significativos, es necesario tener en consideración ciertas limitaciones del estudio para mejorar futuras investigaciones. La muestra recogida forma parte de una institución de Guayaquil, por lo que, no se puede generalizar los resultados con la población de niños residentes en centros de acogida. Aunque los directivos de la institución manifestaron que algunos niños tienen ciertos trastornos, deficiencias motrices y cursan niveles académicos no apropiados para su edad cronológica, no se tuvo acceso a informes de todos los niños sobre su nivel académico, alteraciones cognitivas o motrices desde el nacimiento.

A pesar de que no se pudo aplicar el plan de intervención para conocer si las herramientas propuestas producen mejoras en las funciones cognitivas alteradas, es fundamental que las instituciones lleven a cabo un programa neuropsicológico y terapia psicológica. A partir de la presente investigación, futuros estudios pueden desarrollar un programa de intervención para padres de familia y cuidadores de las casas de acogida para brindar una atención integral a los niños y adolescentes víctimas de maltrato infantil.

\section{Conclusiones}

El maltrato infantil es una problemática actual en el Ecuador que produce consecuencias a nivel cognitivo, conductual y emocional. Para proteger los derechos de los niños, una medida para evitar la exposición de los mismos a nuevas experiencias traumáticas es la 
institucionalización. Este medio brinda protección e intervención integral a los niños y adolescentes víctimas de maltrato infantil o abandono.

Sin embargo, no todas las casas de acogida proporcionan la atención necesaria para cada infante y tampoco pueden satisfacer las demandas requeridas que cada niño tiene en su desarrollo. Por los resultados obtenidos de las pruebas aplicadas se observa una escasa estimulación cognitiva y motriz por parte de los profesionales y cuidadores a cargo de los residentes.

Se concluye que las alteraciones cognitivas de los niños y adolescentes institucionalizados se encuentran, principalmente, en las áreas de Comprensión verbal, Memoria de trabajo y Velocidad de procesamiento. Las funciones cognitivas conservadas son las asociadas a las actividades en el área de Razonamiento perceptual.

Sin embargo, como esta área no presenta deficiencias se infiere que las bajas puntuaciones en el coeficiente intelectual y la discapacidad intelectual de los niños puede ser consecuencia de factores ambientales, es decir, poca estimulación del entorno, discontinuidad en estudios académicos y debido a que los niños han sido expuestos a experiencias traumáticas durante su etapa de desarrollo se ha producido deficiencias cognitivas en la memoria, abstracción y habilidades intelectuales.

Por lo tanto, se recomienda la creación de un programa integral para los cuidadores primarios a cargo de menores de edad institucionalizados en donde incluyan las necesidades de la infancia, desarrollo humano, estimulación motriz y cognitiva; con el objetivo de garantizar un óptimo desarrollo cognitivo, conductual y emocional para los niños y adolescentes. Además, brindar terapia psicológica a los infantes y aplicar las estrategias neuropsicológicas propuestas para estimular las áreas cognitivas alteradas y fortalecer las funciones ejecutivas conservadas.

\section{Referencias Bibliográficas}

American Psychiatric Association. (2014). Manual Diagnóstico y Estadístico de los Trastornos Mentales DSM-V ( $1^{\text {a }}$ Reimpresión). Madrid: Editorial Médica Panamericana.

Arguello, J., Gonzalez, M., \& Joubert, M. (2015). Niños institucionalizados: como desarrollan la identidad y el apego. VII Congreso Internacional de Investigación y Práctica Profesional en Psicología XXII Jornadas de Investigación Décimo Encuentro de Investigadores en Psicología del MERCOSUR. Facultad de Psicología-Universidad de Buenos Aires, Buenos Aires.

Asamblea Nacional. (2014). Los niños, niñas y adolescentes como sujetos de derecho. En C. Nacional, Código de la niñez y adolescencia. Quito, Pichincha, Ecuador.

Butchart, A., Phinney-Harvey, A., Mian, M., Furniss, T., \& Kahane, T. (2009). Prevención del maltrato infantil: Qué hacer, y cómo obtener evidencias. Ginebra: Organización Mundial de la Salud.

Cabrera-Moreno, R. M., \& Zevallos-Herencia, R. C. (2015). Desarrollo del lenguaje comprensivo en niños institucionalizados con abandono parcial y no institucionalizados de 4, 5 y 6 años de edad en la institución educativa de acción conjunta Padre Iluminato en el distrito de 
San Juan de Miraflores (Tesis para obtención del título de Magíster). Pontificia Universidad Católica del Perú.

Cunha, R. V., \& Barreyro, J. P. (2015). Revisión del estado del arte de la depresión, la ansiedad y el apoyo social en torno del tema de niños y adolescentes institucionalizados. Universidad de Ciencias Empresariales y Sociales (UCES), 19(2), 58-73.

Deambrosio, M., de Vázquez, M. G., Arán-Filippetti, V., \& Román, F. (2017). Efectos del Maltrato en la Neurocognición. Un Estudio en Niños Maltratados Institucionalizados y no Institucionalizados. Revista Latinoamericana de Ciencias Sociales, Niñez y Juventud, 16(1), 239-253.

Diaz-Leguizamón, R. S. (2014). Abandono, institucionalización y adopción de tres niños: de la destrucción del psiquismo a su reconstrucción. Tesis de Maestría. Facultad de Psicología de la Pontificia Universidad Javeriana.

Fernández-Daza, M. P. (2013). Características psicológicas y psicopatológicas de adolescentes venezolanos institucionalizados (Tesis doctoral). Universidad de Granada.

Fernández-Daza, M. P., \& Fernández-Parra, A. (2013). Problemas de comportamiento y competencias psicosociales en niños y adolescentes institucionalizados. Universitas psychologica, 12(3).

Fernández-Daza, M. P., \& Fernández-Parra, A. (2017). Problemas de comportamiento, problemas emocionales y de atención en niños y adolescentes que viven en acogimiento residencial. Psychologia: Avances de la Disciplina, 11(1), 57-70.

Fernández, V. (2014). Maltrato infantil: Un estudio empírico sobre variables psicopatológicas en menores tutelados (Tesis doctoral). Universidad de Murcia.

Hernández, R., Fernández, C., y Baptista, C. (2004). Metodología de la investigación. México: McGraw-Hill Interamericana.

Jimeno-Jimenez, M. V. (2016). Experiencias traumáticas en la infancia y su influencia sobre el desarrollo afectivo-social y la memoria autobiográfica en adolescentes institucionalizados comparación con un grupo de control (Tesis doctoral). Departamento de Psicología, Universidad de Castilla-La Mancha, Albacete.

Mansilla-Yuguero, M., Olaya-Meza, C., \& Picazo-Ortega, Á. (2018). ¿Qué papel tiene el apego en la aparición de dificultades emocionales, conductuales y sociales en menores institucionalizados? Psychology, Society, \& Education, 10(2), 163-171.

Ostrosky-Solís, F., Chayo-Dichy, R., Gómez, E., y Flores, J. (2005). ¿Problemas de memoria? Un programa para su estimulación y rehabilitación (1a ed.). México D.F.: LP Editorial.

Ostrosky-Solís, F., Gómez, E., Chayo-Dichy, R., y Flores, J. (2004). ¿Problemas de atención? Un programa para su estimulación y rehabilitación (1a ed.). México D.F.: American Book Store.

Palummo, J. (2013). La situación de niños, niñas y adolescentes en las instituciones de protección y cuidado de América Latina y el Caribe. Fondo de las Naciones Unidas para la Infancia (UNICEF), Panamá.

Quezada-Moncada, C. J. (2016). La intervención de el/la trabajadora social en reinserción familiar de los niños, niñas y adolescentes que se encuentran en acogimiento institucional, en el Hogar de Niños San Vicente de Paúl, Quito, periodo 2013 (Bachelor's thesis). Quito: Universidad Central del Ecuador.

Robalino-Buenaño, M. J., \& Carranza-Villamar, V. J. (2017). La institucionalización y el desarrollo Neuropsicológico en niños de la Casa Hogar San Carlos, periodo abrilseptiembre 2016 (Bachelor's thesis, Universidad Nacional de Chimborazo, 2017).

Esta obra se comparte bajo la licencia Creative Common Atribución-No Comercial 4.0 International (CC BY-NC 4.0) Revista de la Universidad Internacional del Ecuador. URL: https://www.uide.edu.ec/ 
Salinas-Quiroz, F., \& Posada, G. (2015). MBQS: Método de evaluación para intervenciones en apego dirigidas a primera infancia. Revista Latinoamericana de Ciencias Sociales, Niñez y Juventud, 13(2), 1051-1063.

Unicef (2015). Protecting children from violence: a comprehensive evaluation of Unicef's stategies and programme performance. Nueva York.

Wechsler, D. (2007). Escala Wechsler de Inteligencia para Niños IV. México D.F.: Editorial El Manual Moderno. 


\section{Anexo 1: Comprensión verbal}

Actividad 1: Completar categorías

Instrucción: Completar las tablas con la mayor cantidad de palabras teniendo en cuenta la categoría.

\begin{tabular}{|c|c|c|c|}
\hline $\begin{array}{l}\quad \text { Palabras } \\
\text { que empiecen con } \\
\text { C }\end{array}$ & $\begin{array}{l}\quad \text { Palabras } \\
\text { que empiecen con } \\
\text { M }\end{array}$ & $\begin{array}{l}\text { Animales } \\
\text { terrestres }\end{array}$ & Países \\
\hline
\end{tabular}

Actividad 2: Completar oraciones

Instrucción: Se le da una hoja al paciente con oraciones incompletas y se le explica al niño que deberá terminarlas. Si el niño tiene dificultades en la escritura se puede realizar la actividad verbalmente.

Para jugar básquet se necesita una

Para tomar la sopa utilizo la

La persona que corta el cabello se llama

Antes de comer hay que

Para cortar las frutas lo hago con un

Para salir a trotar tengo que ponerme los

Para comprar los vegetales, frutas y carne lo hago en un

Para protegerme del sol me pongo

Observaciones:

Aumentar el nivel de dificultad utilizando otro tipo de contenido en las oraciones o refranes.

\section{Actividad 3: Sinónimos}

Instrucción: Buscar aquellas palabras que tenga un significado parecido y unirlas con las que se encuentran en la segunda columna.

\begin{tabular}{|c|c|}
\hline Económico & Entender \\
\hline Dinero & Sincero \\
\hline Hermoso & Crear \\
\hline Inventar & Barato \\
\hline Honesto & Billete \\
\hline \hline Comprend & Bonito \\
\hline
\end{tabular}


Actividad 4: Definición de palabras

Instrucción: Se le presenta al niño ciertas imágenes y se le explica que se van a emitir definiciones de las mismas y él/ella tendrá que señalar la figura correcta diciendo su nombre.

Utensilio afilado que sirve para cortar la comida.

Estrella que nos da calor y gira alrededor de la tierra.

Prenda que nos cubre del sol.
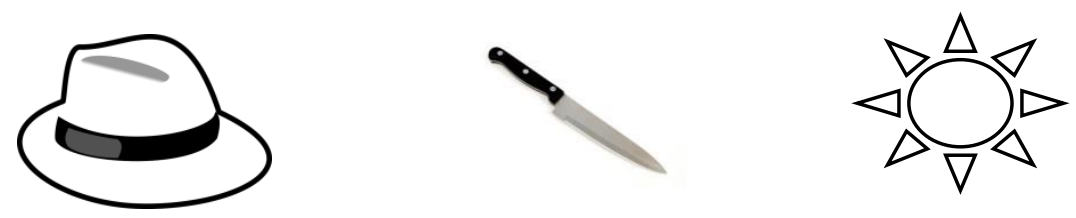

Actividad 5: Ordena las fichas

Instrucción: Poner las fichas en el correcto orden e identificar la palabra faltante. Se puede utilizar los meses del año, planetas, etc.

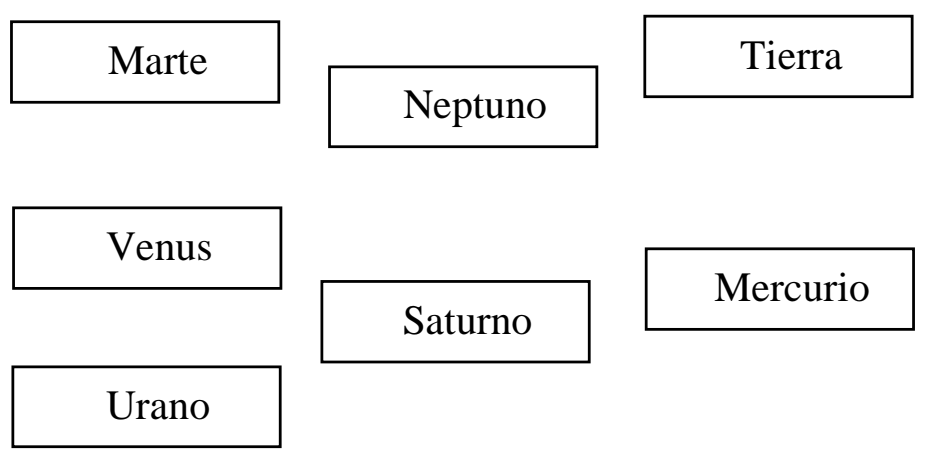

Actividad 6: Ordenar palabras

Instrucción: Ordenar las palabras para formar la oración.

\begin{tabular}{|l|l|l|l|l|l|l|l|l|l|}
\hline feriado & amigos & playa & Mis & yo & el & disfrutamos & en & la & y \\
\hline
\end{tabular}

\begin{tabular}{|l|l||l|l|l|l|l|}
\hline viajes & familia & estas & Los & la & que & aquellos \\
\hline son & mejores & con & \multicolumn{1}{|l}{} \\
\hline
\end{tabular}




\begin{tabular}{|c|c|c|c|c|c|c|c|}
\hline \multicolumn{2}{|c|}{ familia } & importantes & \multirow{2}{*}{$\begin{array}{l}\text { aprendes } \\
\text { donde }\end{array}$} & \multirow{2}{*}{$\frac{\text { los }}{\text { es }}$} & \multirow[t]{2}{*}{$\mathrm{La}$} & \multirow[t]{2}{*}{ valores } & \multirow[t]{2}{*}{ escuela } \\
\hline la & $\mathrm{m}$ & primera & & & & & \\
\hline
\end{tabular}

Actividad 7: Cuentos e historias

Instrucción: Leer el texto en voz alta y contestar las preguntas.

El día en que la familia Pérez había emprendido su excursión a la playa, se encontraron con un stand de concursos. La hija menor, Emilia, decidió concursar y se ganó un perro, al cual lo apodaron Zeus. Con Zeus, la familia Pérez se convirtió en la más famosa del barrio debido a las cualidades que poseía el perro. Aprendió a bailar, seguir órdenes y a ser la mascota más cariñosa. Poco a poco se fue haciendo conocido y contrataban a Zeus para fiestas y circos. La familia Pérez estaba contenta ya que esto aumentaba sus ingresos.

Sin embargo, el día en el que al Sr. Pérez le ofrecieron empleo en Colombia, la familia tuvo que mudarse y despedirse de Zeus al cual lo dejaron al cuidado de su suegra. A los pocos meses, Zeus falleció.

¿Quién y cómo obtuvieron al perro?

¿Por qué se convirtió la familia Pérez en la más famosa?

¿En qué país le ofrecieron trabajo al Sr. Pérez?

¿Qué ocurrió con Zeus después de la partida de la familia?

Fuente: Elaboración propia (basado de "Escala Wechsler de Inteligencia para Niños IV" de Wechsler, 2007. México D.F.: Editorial El Manual Moderno)

\section{Anexo 2: Razonamiento perceptual}

Actividad 1: Patrón

Instrucción: Unir con el patrón adecuado para terminar la serie.

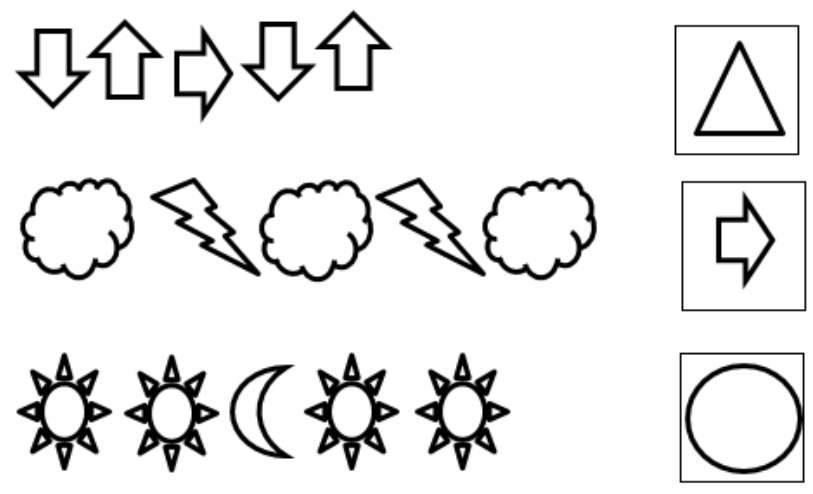



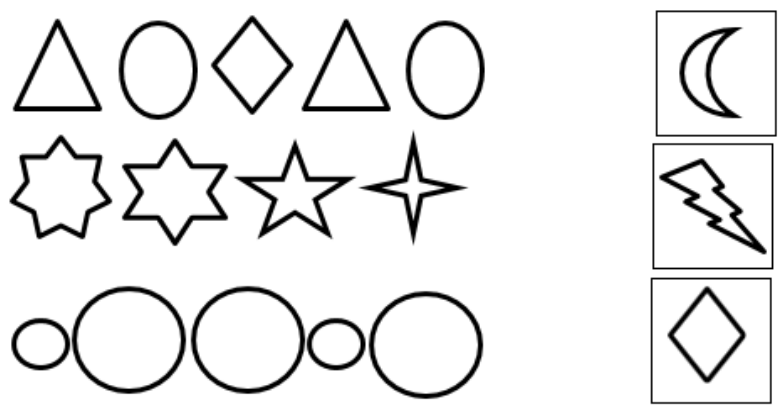

Observaciones:

Aumentar el nivel de dificultad cambiando a matrices según los resultados del paciente.

Actividad 2: Relacionar figuras

Instrucción: Encerrar la figura que tiene algo en común con el modelo.
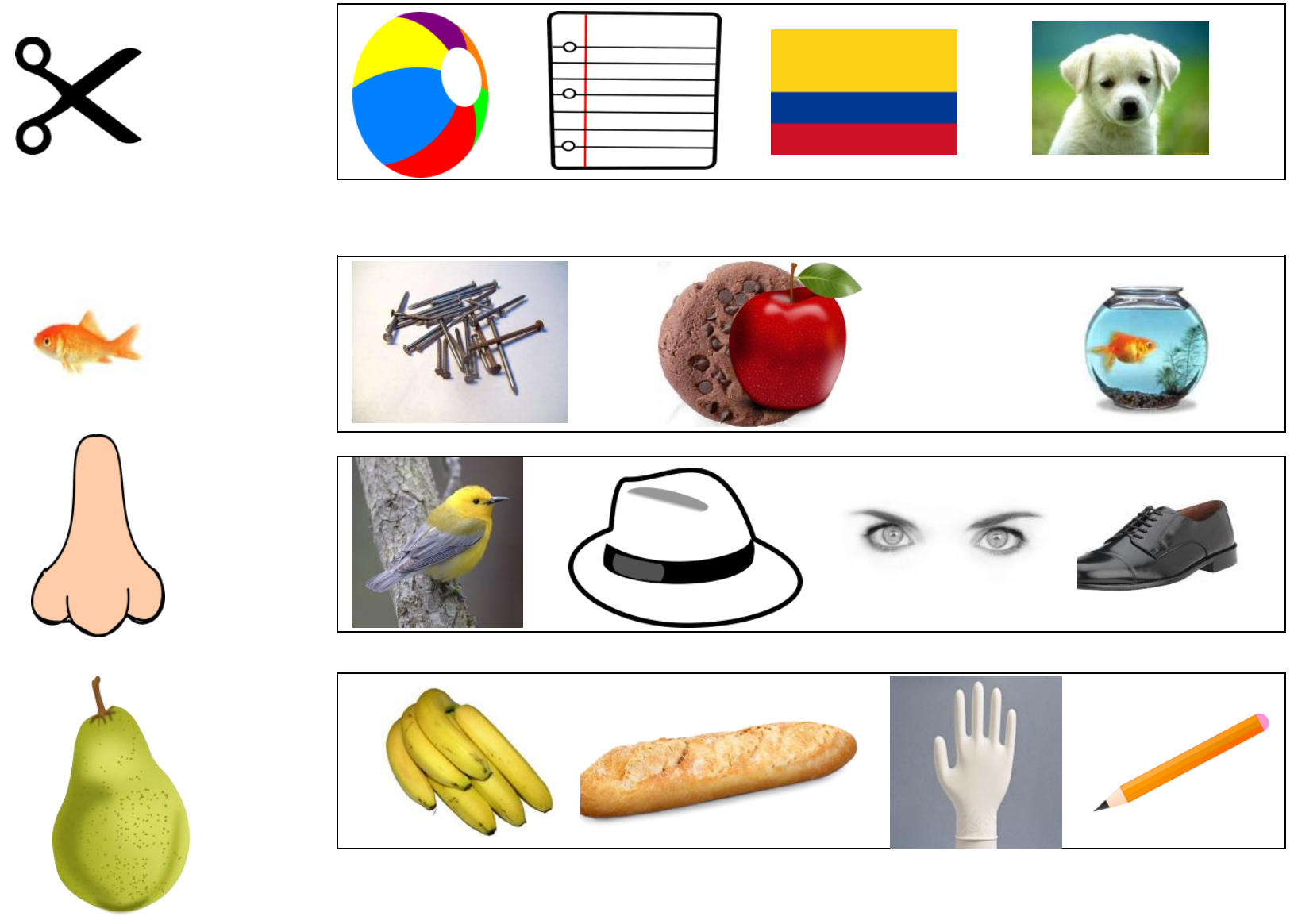

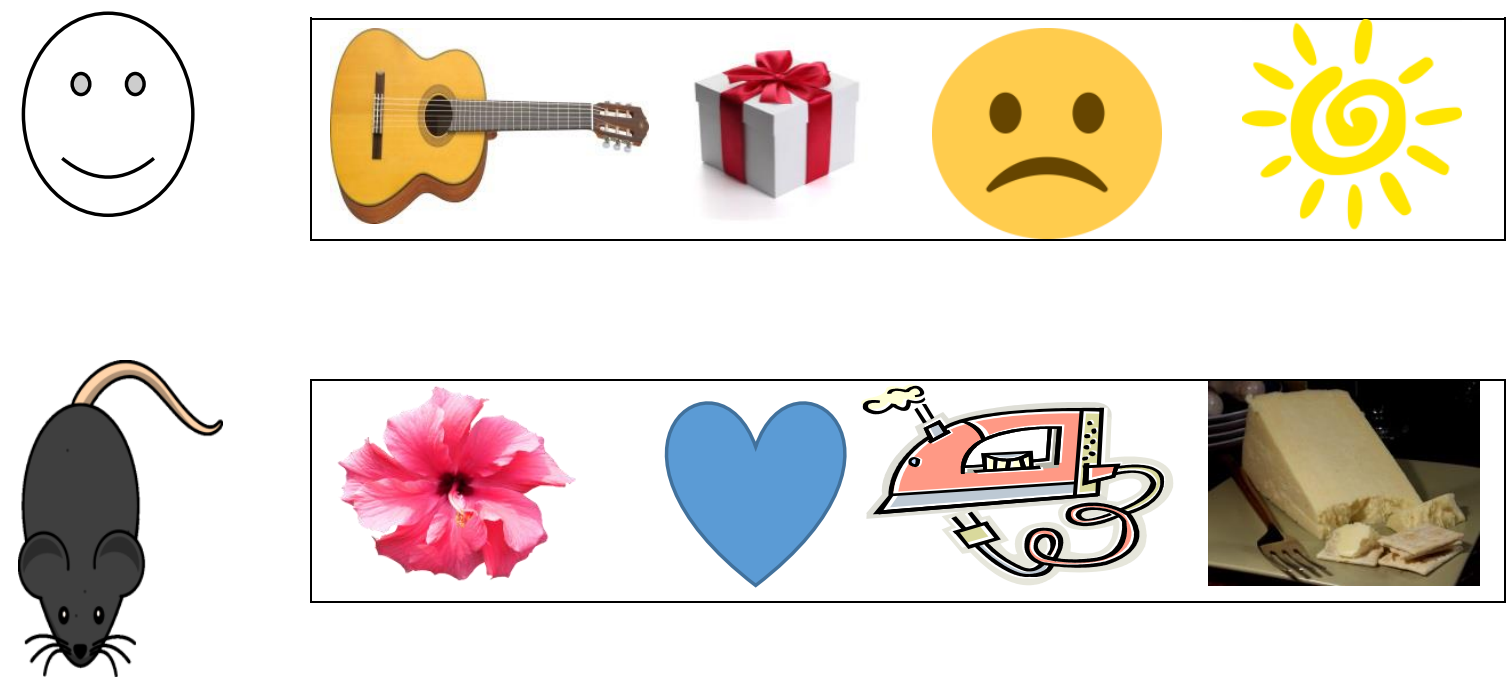

Otras actividades:

- Encontrar las diferencias entre dos dibujos.

- Identificar partes incompletas en figuras.

- Armar rompecabezas.

- Ejercicios figura-fondo: identificar la cantidad de figuras y qué objetos son.

Fuente: Elaboración propia (basado de "Escala Wechsler de Inteligencia para Niños IV" de Wechsler, 2007. México D.F.: Editorial El Manual Moderno)

\section{Anexo 3: Memoria de trabajo}

Actividad 1: Memorizar figuras y signos

Instrucción: Observar los signos y figuras por un tiempo dado. Luego, se le retira la ficha y se le solicita que nombre en orden los signos y después las figuras. Finalmente, que nombre los signos y a qué figura está relacionada y viceversa.
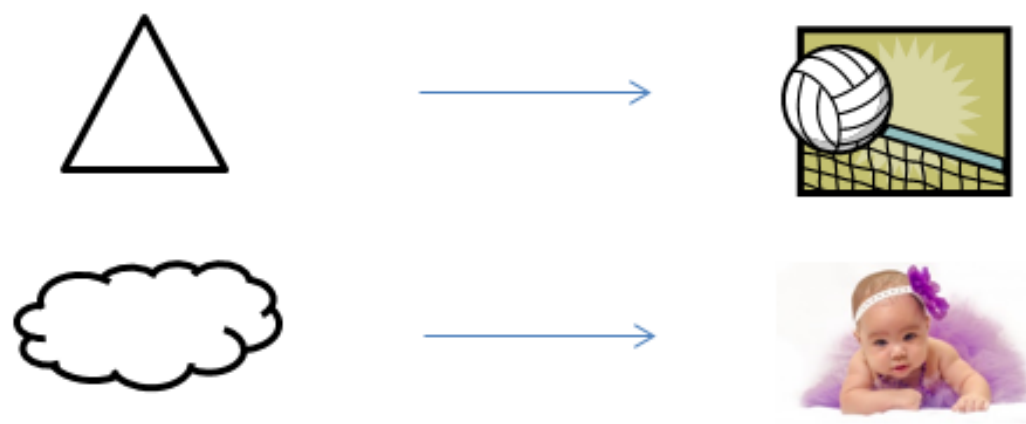

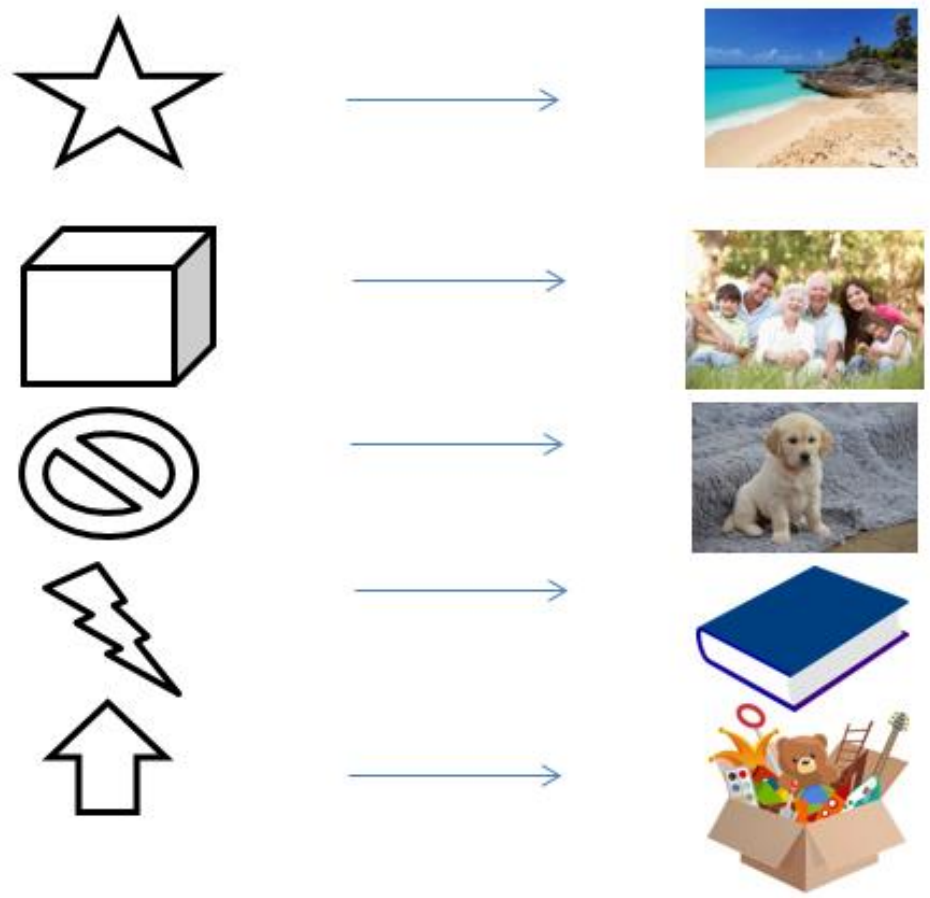

Actividad 2: Juego de categorías

Instrucción: Pedir al niño que elija una categoría (frutas, marcas, animales, países, etc.) y solicitarle que diga un nombre de la categoría elegida. Luego, el terapeuta repetirá el nombre que mencionó el evaluado y añadirá otro. Continuar elaborando una lista con el niño. Se recomienda pedir al paciente que escoja una categoría conocida para él.

Actividad 3: Series de letras

Instrucción: Observar las letras y terminar la serie.

\begin{tabular}{llll}
\hline $\mathrm{A}$ & $\mathrm{B}$ & $\mathrm{Z}$ & $\mathrm{Y}$ \\
\hline $\mathrm{B}$ & $\mathrm{C}$ & $\mathrm{Y}$ & $\mathrm{X}$ \\
\hline
\end{tabular}


Actividad 4: Completar series

Instrucción: Continuar las series de letras y números según las indicaciones del terapeuta. Aumentar el nivel de dificultad según los resultados del niño. Ejemplos:

- $\quad 1 \mathrm{~A}, \mathrm{~B} 2,3 \mathrm{C}, \mathrm{D} 4 \ldots$.

- $\mathrm{AB} 1, \mathrm{CD} 2, \mathrm{EF} 3, \mathrm{GH} 4 \ldots$

- $1 \mathrm{AB}, 2 \mathrm{DE}, 3 \mathrm{GH} .$.

Actividad 5: Memorizar tareas

Instrucción: Memorizar la lista de tareas que le asignó la mamá a sus hijos y completar los espacios en blanco.

La mamá les pidió a sus hijos que la ayuden hacer algunos de los quehaceres de la casa:

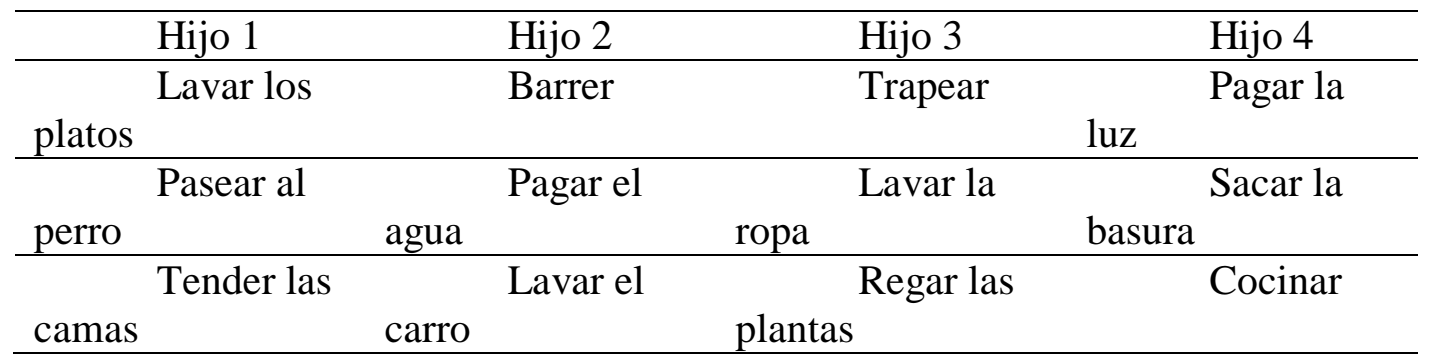

Cuando llegó la mamá, los hijos notaron que les faltó una tarea por hacer. Completa la tarea que les faltó:

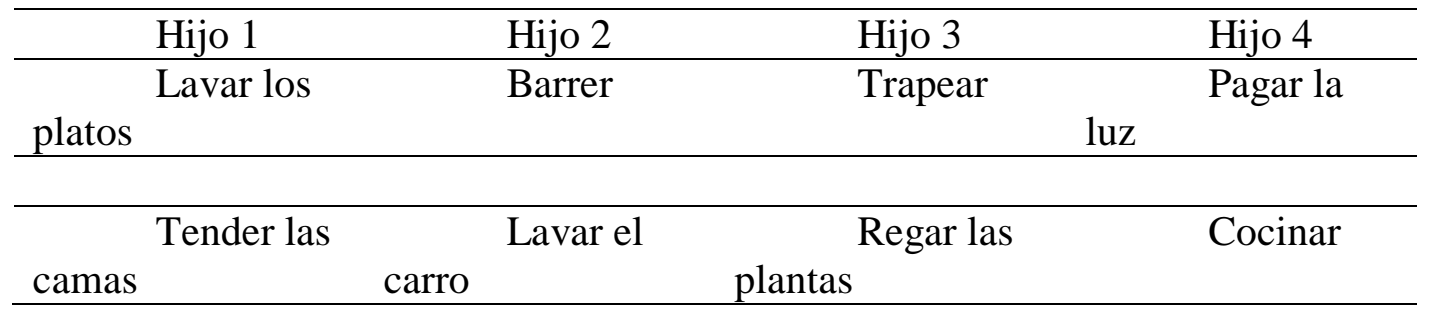

Fuente: Elaboración propia (basado de: “¿Problemas de memoria? Un programa para su estimulación y rehabilitación" (1 $1^{\mathrm{a}}$ ed.) de Ostrosky-Solís, F., Chayo-Dichy, R., Gómez, E., y Flores, J., 2005. México D.F.: LP Editorial).

\section{Anexo 4: Velocidad de procesamiento}

Actividad 1: Números con símbolos

Instrucción: Asignar el número correspondiente a cada símbolo en 50 segundos. 

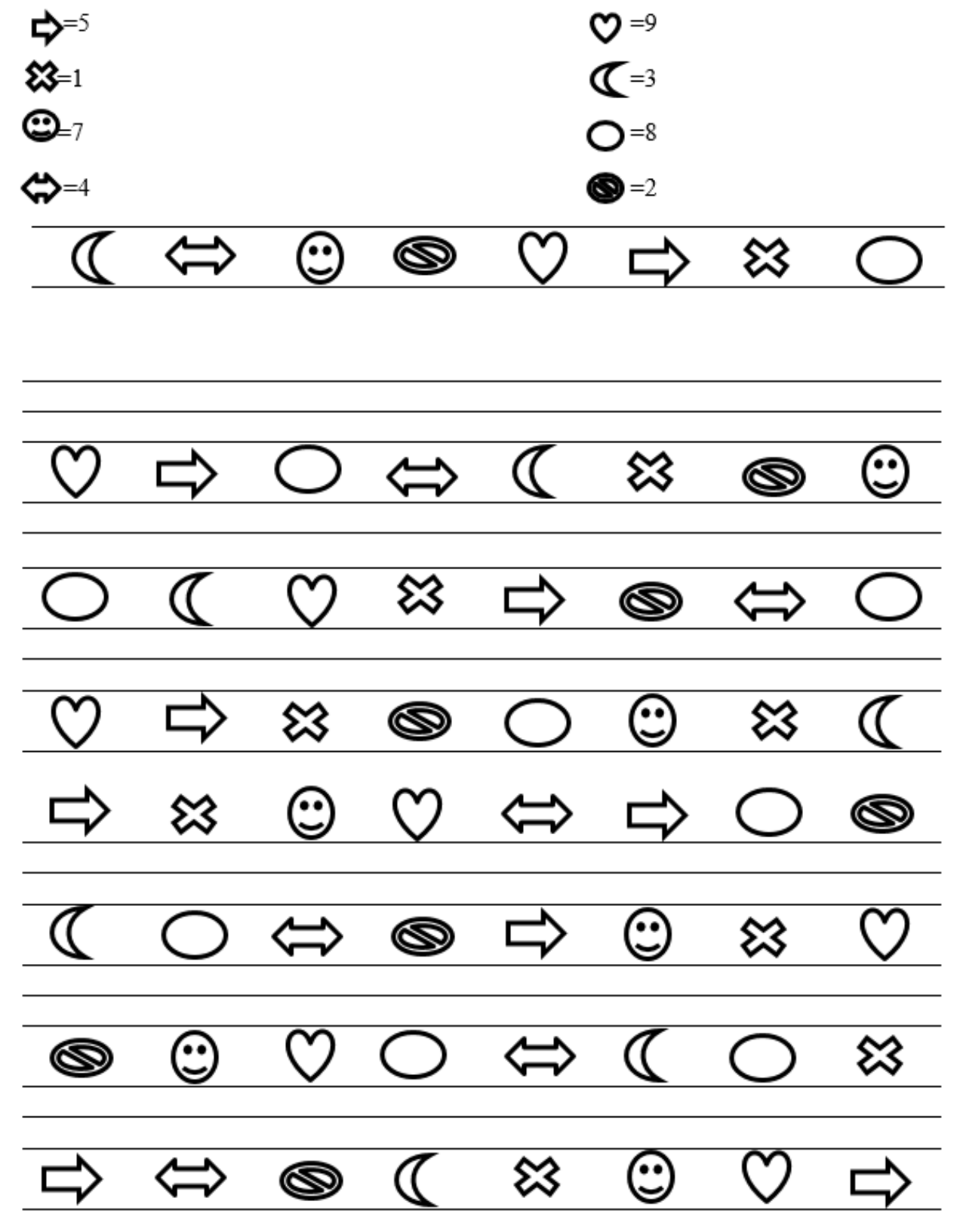

Observaciones:

- Aumentar la dificultad de la actividad incrementando la cantidad de símbolos a completar y reducir el tiempo dado.

- Cambiar la consigna: asignar el símbolo correspondiente a cada número.

Actividad 2: Encerrar símbolos

Instrucción: Encerrar el símbolo igual al modelo en un minuto. 
A

\begin{tabular}{|c|c|c|c|c|c|c|c|c|c|c|c|c|c|}
\hline Å & A & ’Ạ & Ac & ’̨̧ & Ą) & ז̃A & זÅ & A A & Ą & "A & זAุ & A A & A A \\
\hline ̊A & ’ÅA & ÅA & ¿ุ̊ & A & "Ạ & $\stackrel{A}{A}$ & ’Ą & A & "Ạ & A & "A & & \\
\hline A & ’Å & ̃å & A & ’Ạ & ז̊A & A & Å & "A & Ą & A & "A & A A & ’Ạ \\
\hline Å & ב̃A & ’Å & Aa & A & ’A & ¿̃A & Aa & A & "A & ז̃A & A & A A & Å \\
\hline ̊A & A & A & ’Ạ & A & ?ָA & בA A & Å & A & "A & ’Ạ & A A & זÅ & A \\
\hline Å & A A & ’Ą & זA A & Å & క̊A & ’Å & A & ’Å & "A Ą & A & ¿̊A & Å & ’Ą \\
\hline ז̃A & A & A & ז̃A & Å & ’Ą & A A & A & 'ĄA & Aa & ’Å & ?̃A & ̃A & "A \\
\hline ’̨̧ & A & ז̃A & 'A & "A & ז̃A & A & A & ̃A & ’̨̧ & Ą & ז̃ & "A & A \\
\hline
\end{tabular}

Actividad 3: Encerrar categorías

Instrucción: Encerrar las imágenes que simbolicen animales en 40 segundos.

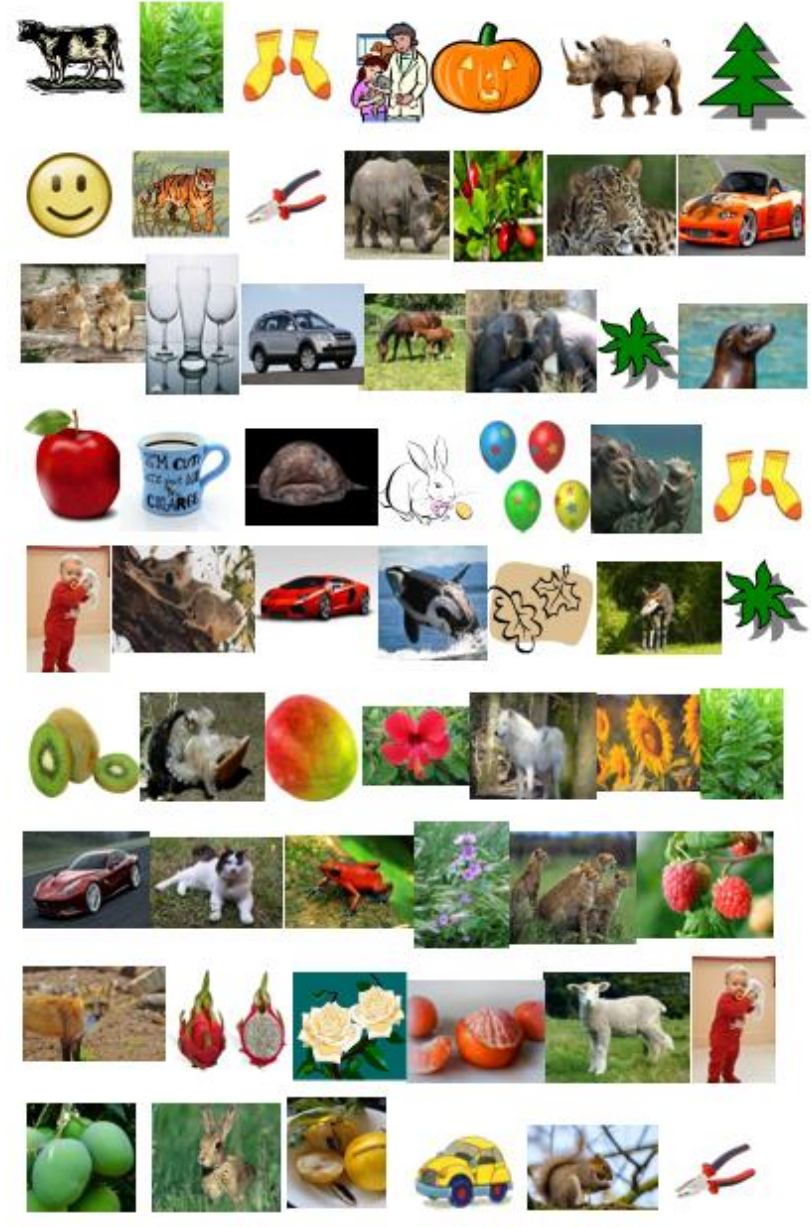




\section{Observaciones:}

- Aumentar el nivel de dificultad indicando al evaluado que deberá encerrar animales acuáticos, terrestres o aéreos.

Actividad 4: Ubicar los signos

Instrucción: Se le muestra al evaluado la tabla con los triángulos por determinado tiempo y se le retira. Luego, se le presenta la tabla con dígitos y se le pide que mencione las letras o números en los cuales estaban ubicados los triángulos.

\begin{tabular}{llllll}
\hline $\mathrm{a}$ & $\mathrm{b}$ & $\mathrm{c}$ & $\mathrm{d}$ & $\mathrm{e}$ & $\mathrm{f}$ \\
\hline $\mathrm{g}$ & $\mathrm{h}$ & $\mathrm{i}$ & $\mathrm{j}$ & $\mathrm{k}$ & 1 \\
\hline $\mathrm{m}$ & $\mathrm{n}$ & $\mathrm{o}$ & $\mathrm{p}$ & $\mathrm{q}$ & $\mathrm{r}$ \\
\hline $\mathrm{s}$ & $\mathrm{t}$ & $\mathrm{u}$ & $\mathrm{v}$ & $\mathrm{w}$ & $\mathrm{x}$ \\
\hline $\mathrm{y}$ & $\mathrm{z}$ & 1 & 2 & 3 & 4 \\
\hline
\end{tabular}

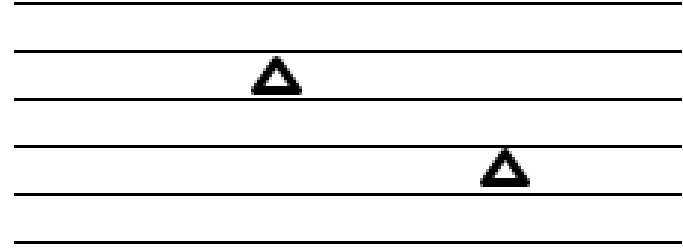

\section{Observaciones:}

- Aumentar el nivel de dificultad incrementando la cantidad de signos.

Actividad 5: Operaciones numéricas con símbolos

Instrucción: Sumar o restar los símbolos de acuerdo a la cantidad de cada uno.

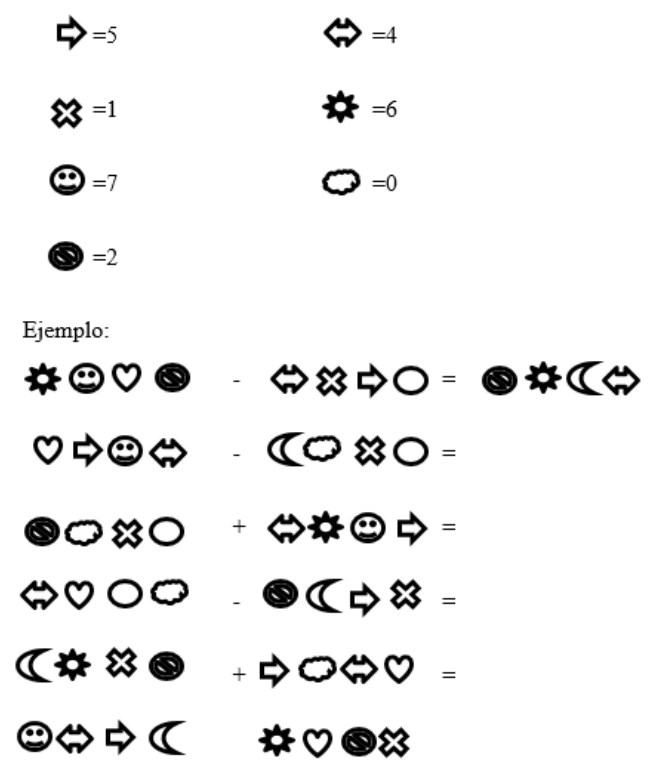

Fuente: Elaboración propia (basado de: “¿Problemas de atención? Un programa para su estimulación y rehabilitación” (1 $1^{\mathrm{a}}$ ed.) de Ostrosky-Solís, F., Gómez, E., Chayo-Dichy, R., y Flores, J., 2004. México D.F.: American Book Store). 